\title{
APLIKASI JAVA PENDATAAN WARGA DAN KAS RT 015 RW 002 BATU AMPAR
}

\author{
Faisal Setiadi ${ }^{1}$, Gilang Ryan Fernandes ${ }^{2}$, Iwan Budiarso ${ }^{3}$ \\ ${ }^{1,2,3}$ Universitas Indraprasta PGRI \\ Jalan Raya Tengah No 80, Kelurahan Gedong, Pasar Rebo, Jakarta Timur \\ 1.
}

\begin{abstract}
ABSTRAK
Perkembangan teknologi dan informasi yang berkembang pesat dari tahun ke tahun menuntut di setiap instansi pemerintahan, swasta, maupun lingkup warga untuk mengikuti perkembangan tersebut. Dengan penggunaan sistem secara komputerisasi dan digitalisasi semakin mempermudah instansi dalam melakukan pengolahan data serta lebih efisiensi dan efektivitas kerja. Informasi penduduk merupakan faktor yang penting dalam lingkup Rukun Tetangga karena dengan informasi penduduk tersebut dapat memudahkan dalam pelayanan dan penyuluhan informasi terkait kepada masyarakat setempat. Implementasi sistem komputerisasi dilakukan karena pendataan warga masih menggunakan metode manual atau tulis tangan, belum adanya informasi pendataan balita dalam rangka pemberian imunisasi, terjadi penumpukan berkas-berkas warga setelah pendataan, yang berakibat lamanya pencarian data ketika ingin mengambil atau mencari data warga dan data lain-lain. Penelitian bertujuan untuk menganalisis metode yang digunakan dalam sistem pendataan warga yang berjalan saat ini untuk digantikan dan diimplementasikan menggunakan sistem pendataan secara komputerisasi. Metode kualitatif dan waterfall digunakan dalam metode pengembangan sistem. Wawancara dan observasi dipilih dalam menganalisis metode penelitian yang akan digunakan untuk pengembangan sistem pendataan warga secara komputerisasi. Membantu ketua Rukun Tetangga dan pengurus dalam pengelolaan data warga menjadi simpulan penulis dalam perancangan dan pengembangan sistem pendataan warga secara komputerisasi agar sistem yang penulis ciptakan berguna bagi ketua Rukun Tetangga dan pengurusnya.
\end{abstract}

Kata Kunci: Sistem Pendataan Warga, Teknologi dan Informasi, Metode Waterfall

\section{ABSTRACT}

The development of technology and information that is growing rapidly from year to year requires every government agency, private sector, and community to follow these developments. With the use of computerized and digitized systems, it is easier for agencies to process data and increase work efficiency and effectiveness. Population information is an important factor in the scope of the Neighborhood Association because the information on the population can facilitate the service and counseling of related information to the local community. The implementation of the computerized system was carried out because citizen data collection was still using manual or handwritten methods, there was no information on data collection for toddlers in the context of giving immunizations, there was a buildup of citizen files after data collection, which resulted in a long search for data when wanting to retrieve or search for citizen data and other data. other. This study aims to analyze the methods used in the current citizen data collection system to be replaced and implemented using a computerized data collection system. Qualitative and waterfall methods are used in the system development method. Interviews and observations were chosen in analyzing the research methods that will be used for the development of a computerized citizen data collection system. Helping the head of the Neighborhood Association and the administrators in managing citizen data is the author's conclusion in the design and development of a computerized citizen data collection system so that the system that the author creates is useful for the head of the Neighborhood Association and its administrators.

Key Word: Citizen Data Collection System, Technology and Information, Waterfall Method

\section{PENDAHULUAN}

Pada dasarnya sistem administrasi kependudukan merupakan bagian dari sistem administrasi negara, yang mempunyai peranan sangat penting dalam pemerintahan untuk mengelola data kependudukan. Setiap orang berhak mendapatkan pelayanan administrasi kependudukan dengan baik dan mudah. Peningkatan kesadaran penduduk dan peran serta untuk ikut mendukung

$\begin{array}{llr}\text { perencanaan } & \text { pembangunan } & \text { sistem } \\ \text { administrasi } & \text { kependudukan } & \text { guna } \\ \text { meningkatkan pelayanan terhadap publik. } & \text { peran } \\ \text { Sejalan dengan tujuan penyelenggaraan } \\ \text { administrasi kependudukan, maka } \\ \text { pendaftaran penduduk dan pencatatan sipil } \\ \text { merupakan bagian penting dari sistem } \\ \text { administrasi kependudukan. }\end{array}$


Sistem adalah kumpulan/grup dari sub sistem/bagian/komponen apa pun, baik fisik ataupun non fisik yang saling berhubungan satu sama lain dan bekerja sama secara harmonis untuk mencapai satu tujuan tertentu (Djahir dan Pratita. 2015 : 6). Lalu informasi adalah sekumpulan data atau fakta yang diorganisasi atau diolah dengan cara tertentu sehingga mempunyai arti bagi penerima (Anggraeni \& Irviani, 2017 : 13). Dalam hal tersebut, sistem informasi adalah sistem yang mempunyai prosedur dan koordinasi secara terstruktur guna mencapai target atau sasaran yang di capai. Adapun administrasi kependudukan adalah rangkaian kegiatan penataan dan penertiban dalam penerbitan dokumen dan data kependudukan melalui pendaftaran penduduk, pencatatan sipil, pengelolaan informasi administrasi kependudukan serta pendayagunaan hasilnya untuk pelayanan publik dan pembangunan sektor lain (Undang-Undang Republik Indonesia Nomor 24 Tahun 2013 Tentang Perubahan Atas Undang-Undang Nomor 23 Tahun 2006 Tentang Administrasi Kependudukan Dengan, 2017 : 53). Dengan adanya aplikasi membantu sistem pendataan warga menangani permasalahan yang ada saat ini, serta meningkatkan efektivitas pendataan secara kompleks.

\section{METODE PENELITIAN}

Peneliti menggunakan metode kualitatif, karena dengan metode kualitatif, di harapkan adanya analisis, proses sistem dapat membantu pekerjaan lebih mudah di bandingkan dengan sistem sebelumnya. Berikut metode pengumpulan data berdasarkan metode penelitian kualitatif:

\section{Observasi}

Peneliti mengamati cara ketua RT mengumpulkan data-data penting yang dibutuhkan untuk melakukan pendataan secara manual menggunakan media buku tulis dan pulpen untuk menulis.

2. Wawancara

Dalam implementasi wawancara, narasumber dipilih berdasarkan yang paham akan alurnya sistem pendataan yang sedang dibuat.

Setelah penulis melakukan wawancara, observasi dengan pengurus RT dan warga, penulis beranggapan bahwa pendataan warga masih menggunakan metode manual, seperti penulisan, pengelompokan data berdasarkan ketentuan yang diatur pengurus RT. Penulis ingin mencoba menganalisis kekurangan yang timbul dari adanya sistem pendataan yang masih menggunakan metode lama, dan mengeksplorasi kekurangan tersebut untuk dijadikan acuan dalam pengembangan sistem pendataan warga secara komputerisasi.

Untuk mencapai hasil yang sesuai dengan perancangan sistem, peneliti mencoba menjelaskan langkah-langkah yang di tuliskan dan dijelaskan pada metode Waterfall atau Air Terjun dalam perancangan sistem pendataan warga. Model waterfall adalah model klasik yang bersifat sistematis, berurutan dalam membangun software (Pressman, $2015: 42$ ) dan digunakan dalam bentuk menurun dan langkah demi langkah untuk melakukan pendekatan sistematis dan berurutan sehingga menemukan hasil yang sesuai dalam melakukan pengembangan sistem.

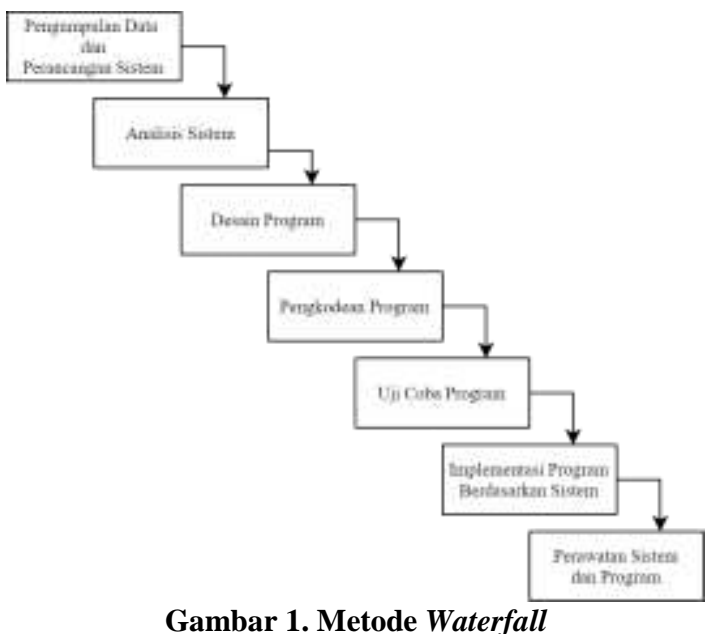

HASIL DAN PEMBAHASAN

Berdasarkan poin metode penelitian yang sudah dijabarkan, penulis memberikan solusi yang ada pada sistem pendataan warga dengan membuat alur sistem pendataan secara kompleks dan komputerisasi. Alur tersebut menggunakan use case diagram, activity diagram, dan sequence diagram. Untuk basis data menggunakan Entity Relationship Diagram (ERD), Transformasi ERD ke LRS, serta Logical Record Structure.

Use Case Diagram merupakan pemodelan untuk kelakuan (behaviour) sistem informasi yang akan dibuat". Dari hasil analisa-analisa permasalahan serta alternatif permasalahan 
yang penulis temukan, di bawah ini penulis menjabarkan use case diagram berdasarkan 3 kategori utama, yaitu master, transaksi, dan laporan (Shalahuddin, 2014 : 155). Berikut ini gambar use case diagram yang telah penulis buat:

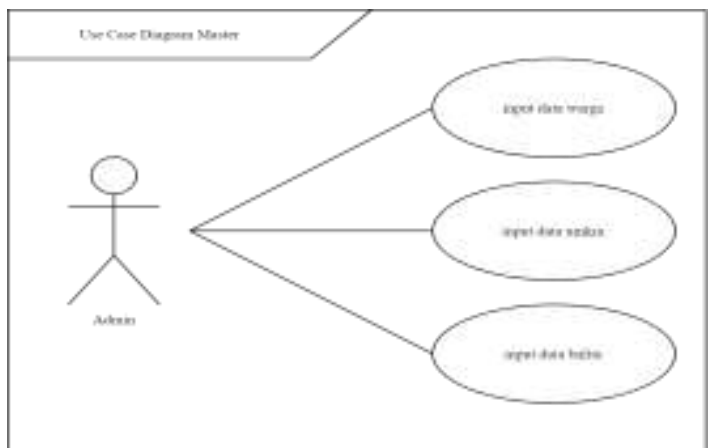

Gambar 2. Use Case Diagram Data Master

Berdasarkan use case diagram data master di atas, admin memiliki hak akses atas data master, yakni data warga, data umkm, serta data balita.

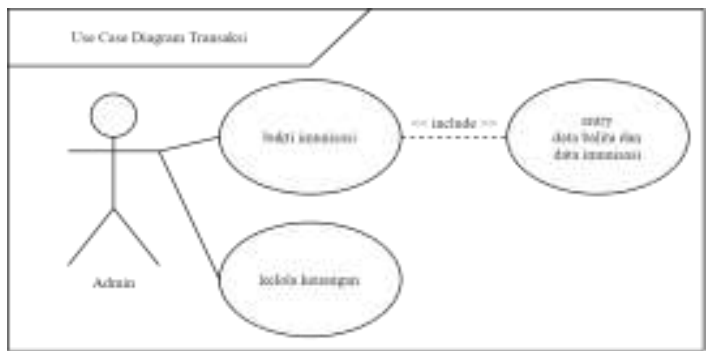

Gambar 3. Use Case Diagram Data Transaksi

Gambar use case diagram transaksi di atas, admin melakukan akses terhadap transaksi imunisasi dan keuangan, di mana transaksi imunisasi, termasuk data balita dan data imunisasi, lalu transaksi keuangan sebagai pengelolaan.

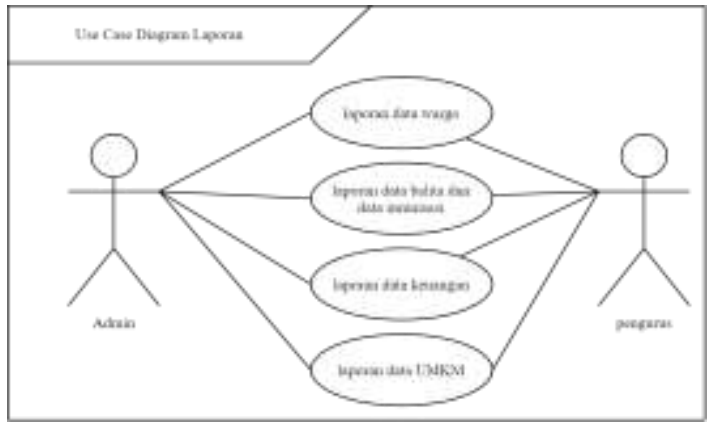

Gambar 4. Use Case Diagram Data Laporan

Dari gambar use case diagram laporan, admin memiliki hak akses untuk mencetak laporan, dan pengurus mendapatkan hak untuk mendapatkan laporan yang telah di cetak oleh admin.

Activity diagram memodelkan workflow proses bisnis dan urutan aktivitas dalam sebuah proses. Diagram ini sangat mirip dengan flowchart karena memodelkan workflow dari suatu aktivitas lainnya atau dari aktivitas ke status (Tohari, 2014 : 114). Activity diagram menggambarkan segala rangkaian aktivitas yang terjadi pada suatu proses operasi dan menjelaskan secara jelas rangkaian aktivitas tersebut. Berikut penjelasan activity diagram dari sistem:

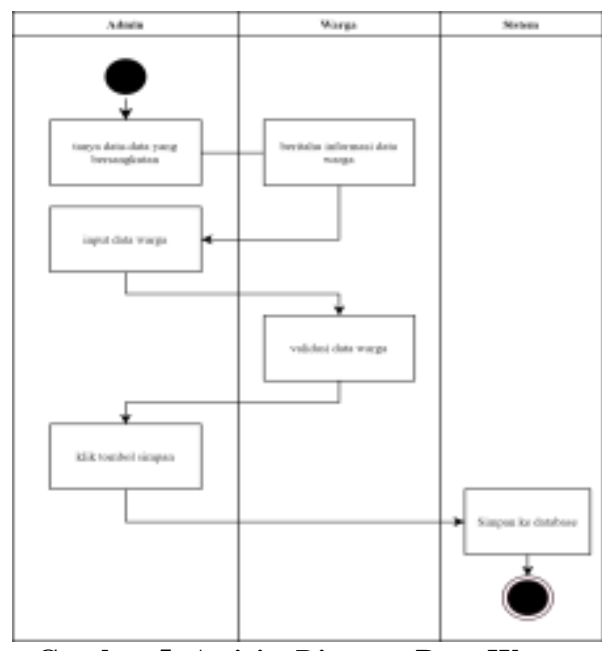

Gambar 5. Activity Diagram Data Warga

Pada diagram aktivitas data warga, admin melakukan pendataan dengan menanyakan data yang dibutuhkan dalam proses pendataan warga. Setelah data tersebut di terima, admin melakukan input data dan sistem akan menyimpan data tersebut.

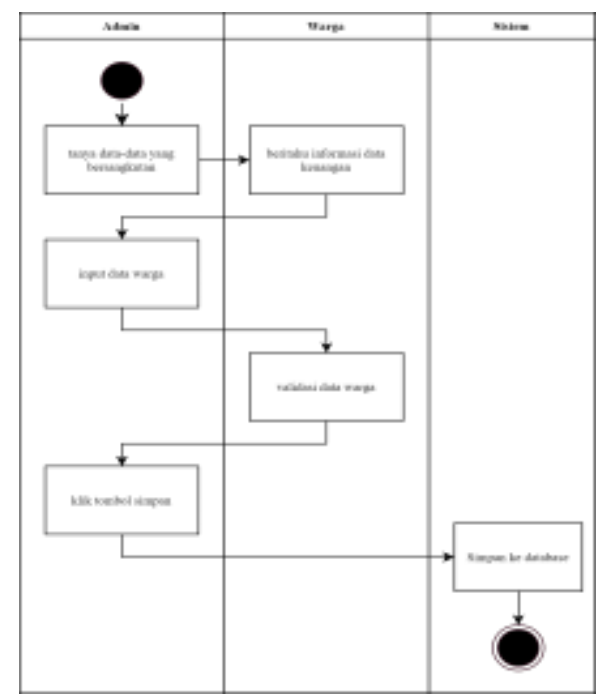

Gambar 6. Activity Diagram Data Keuangan 
Pada diagram aktivitas data warga, admin melakukan pendataan dengan menanyakan data yang dibutuhkan dalam proses pendataan keuangan, termasuk kas RT. Setelah data tersebut di terima, admin melakukan input data dan sistem akan menyimpan data tersebut.

Setelah melakukan aktivitas diagram, penulis melakukan rancang basis data yang akan di sematkan dalam sistem pendataan warga, yaitu Entity Relationship Diagram (ERD), Transformasi ERD ke LRS, dan Logical Record Structure (LRS).

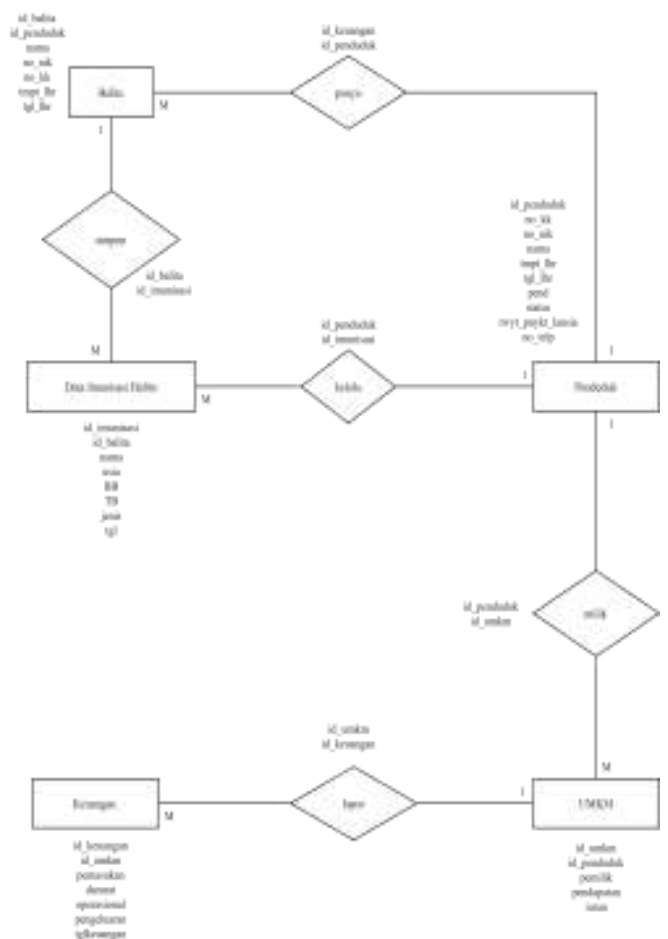

Gambar 7. ERD yang Dirancang Dalam Sistem Pendataan

Dalam gambar di atas merupakan Entity Relationship Diagram (ERD) yang sedang di rancangkan. ERD adalah tools yang digunakan untuk melakukan pemodelan data secara abstrak dengan tujuan untuk mendeskripsikan atau menggambarkan struktur dari data yang digunakan (Mulyani, 2016 : 100). Penjelasan tersebut dapat di lihat dari gambar yang memiliki lima entitas dan menghasilkan 5 kardinalitas yang masingmasing mempunyai keterkaitan antar entitas.

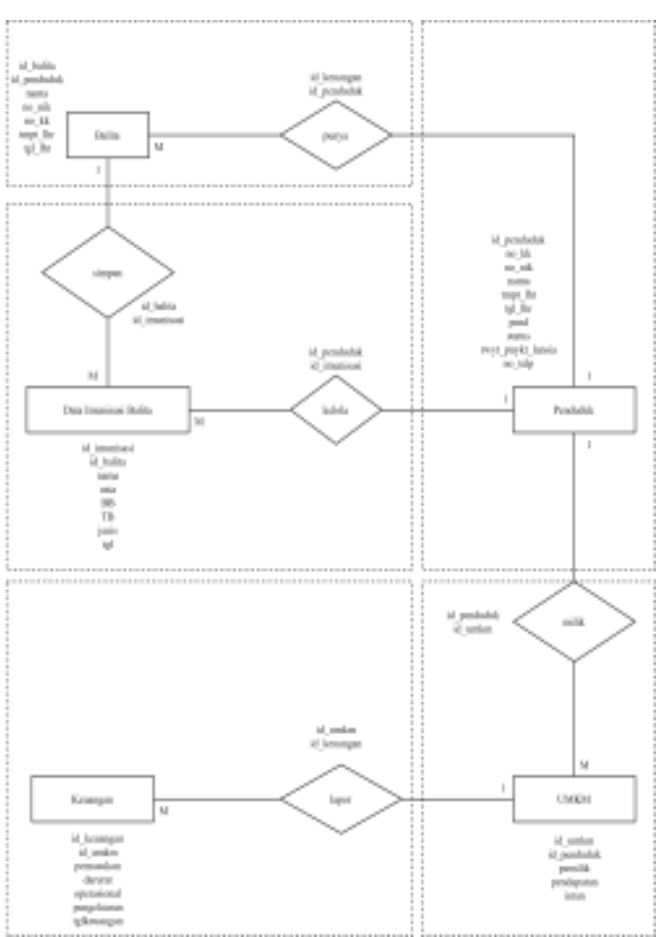

Gambar 8. Transformasi ERD ke LRS yang Dirancang dalam Sistem Pendataan

Di atas ini menggambarkan Transformasi ERD ke LRS. Dalam tahapan konversi ERD ke LRS sebuah model sistem yang di gambarkan dengan sebuah ERD akan mengikuti pola penelitian tertentu (Wulandari, 2013 : 15-16). Dalam gambar tersebut, Entitas yang memiliki banyak populasi dengan huruf M (Many), sedangkan entitas yang memiliki 1 populasi dengan angka 1 (One).

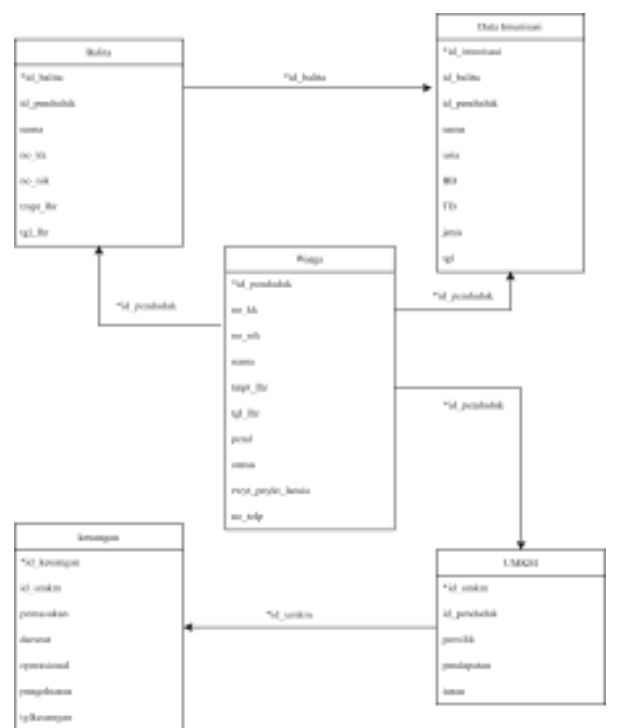

Gambar 9. LRS yang Dirancang dalam Sistem Pendataan

LRS adalah sebuah model sistem yang digambarkan dengan sebuah diagram ER akan 
mengikuti pola atau aturan permodelan tertentu dalam kaitannya dengan konveksi ke LRS (Hasugian \& Shidiq, 2012 : 608). Gambar di atas ini mengacu pada gambar transformasi ERD ke LRS yang terdiri dari beberapa tabel yang ada di database. Tabel tersebut berisikan beberapa field yang setiap tabel mempunyai 1 atau lebih field khusus yang disebut primary key yang berfungsi sebagai penghubung antara field satu dengan field yang lain nya.

Berdasarkan analisa dan pembahasan yang telah dijelaskan di atas, penulis membuat sistem informasi pendataan warga dan kas untuk memudahkan proses pendataan pada RT 015 yang selama ini menggunakan metode manual. Berikut tampilan layar sistem pendataan yang telah penulis buat dalam aplikasi java:

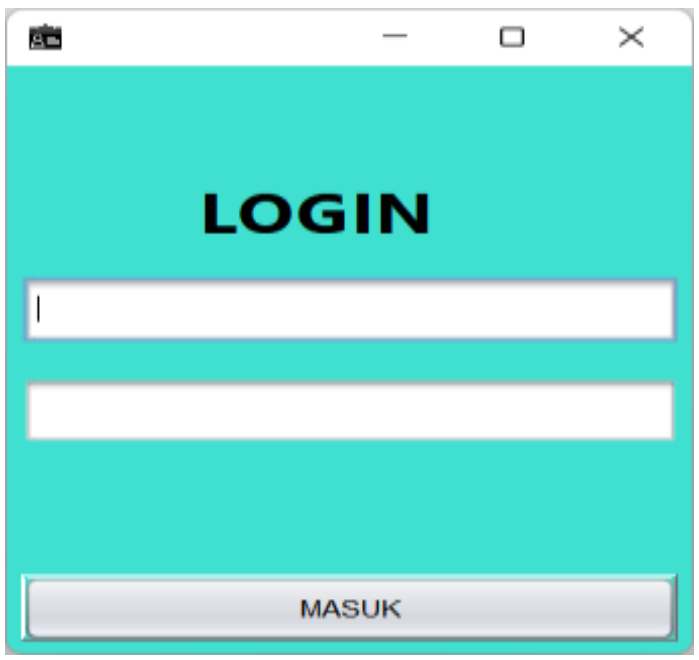

Gambar 10. Tampilan Layar Login

Tampilan layar di atas ini berfungsi sebagai validasi atas hak akses sebelum membuka halaman utama. Dalam hal ini, hanya admin yang memegang kendali atas aplikasi.

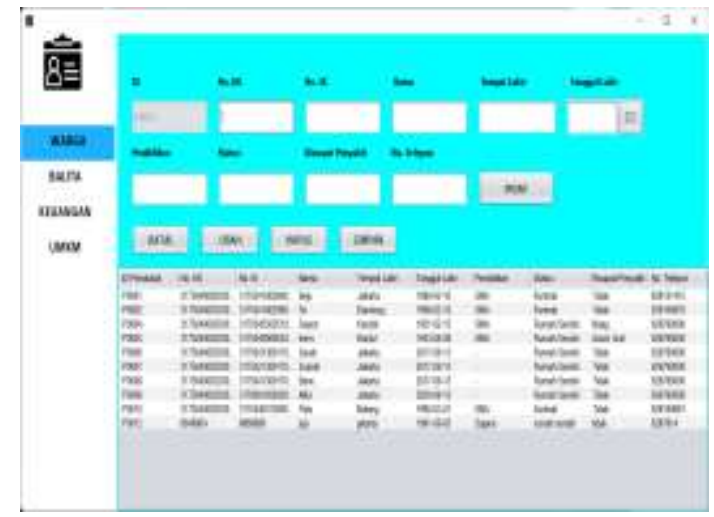

Gambar 11. Tampilan Layar Data Warga
Tampilan layar di atas ini berfungsi sebagai form yang berisikan field-field yang telah di sesuaikan dengan basis data yang sebelumnya telah di bahas dalam LRS dan di-input-kan ke dalam basis data

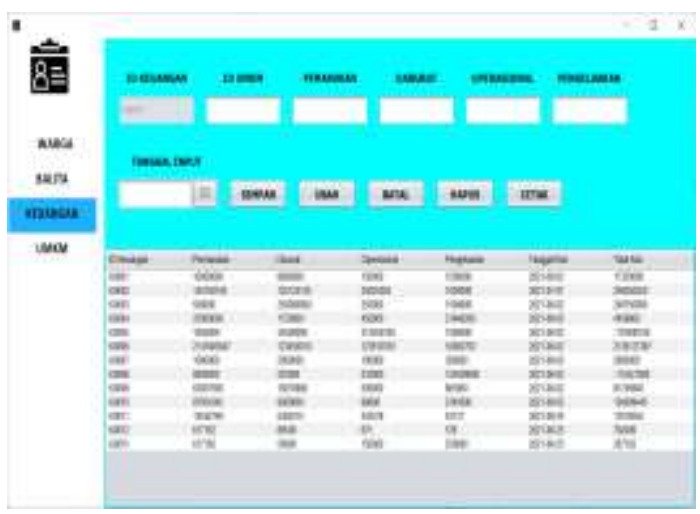

Gambar 12. Tampilan Layar Data Keuangan

Tampilan layar di atas ini berfungsi sebagai form yang berisikan beberapa field yang telah di sesuaikan dengan basis data yang sebelumnya telah di bahas dalam LRS.

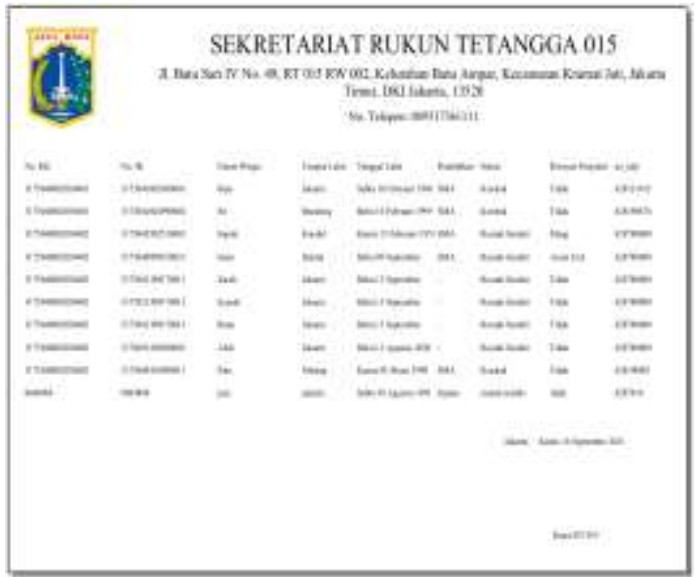

Gambar 13. Tampilan Laporan Data Warga

Tampilan layar laporan berfungsi sebagai output atau keluaran data yang telah di simpan di dalam database.

Sequence diagram atau diagram sekuen menggambarkan kelakuan objek pada use case dengan mendeskripsikan waktu hidup objek dan message yang dikirim dan diterima antar objek (Sukamto dan Shalahuddin, 2013 : 165). Dalam hal itu, penulis menjelaskan sequence diagram yang terdapat pada aplikasi di bawah ini: 


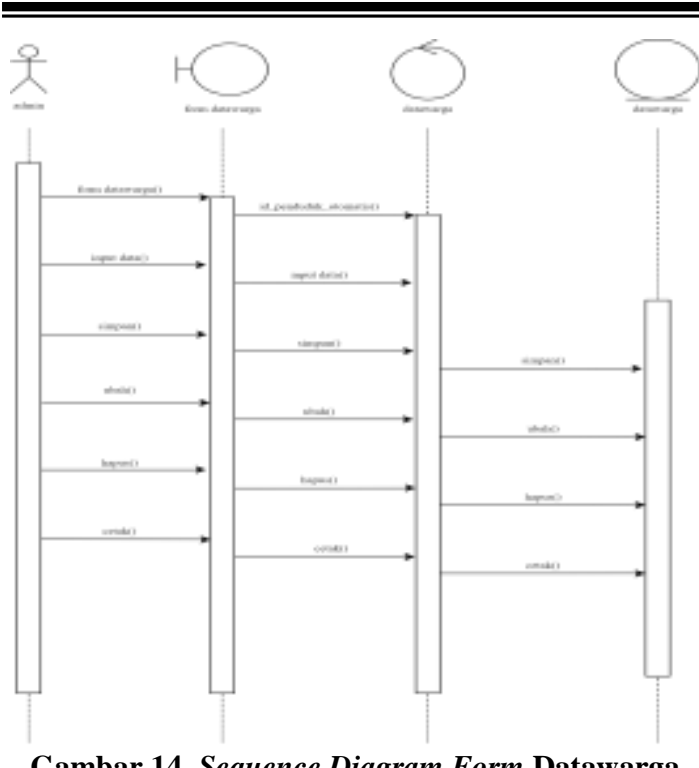

Gambar 14. Sequence Diagram Form Datawarga

Di atas ini berfungsi sebagai informasi atas alur sistem yang terjadi di dalam aplikasi. Dalam alur tersebut, terdapat fungsi simpan, ubah, hapus, dan cetak.

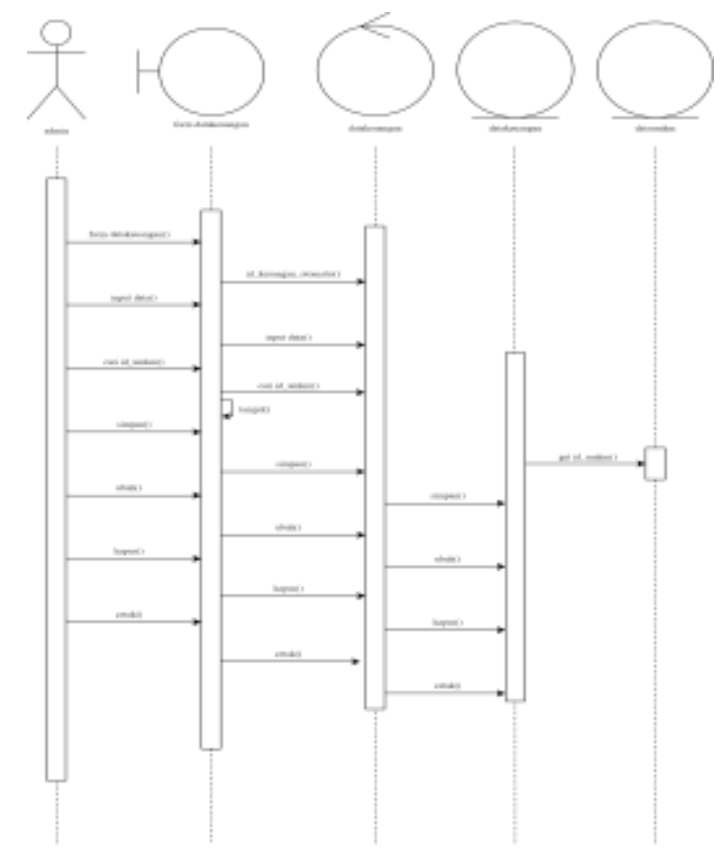

Gambar 15. Sequence Diagram Form Datakeuangan

Di atas ini berfungsi sebagai informasi atas alur sistem yang terjadi di dalam aplikasi. Dalam alur tersebut, terdapat fungsi simpan, ubah, hapus, dan cetak. Fungsi pencarian data umkm otomatis include di dalam field pada form data keuangan.

\section{SIMPULAN DAN SARAN}

Dari hasil rancangan sistem berbasis aplikasi java desktop yang telah peneliti lakukan sebelumnya, peneliti membuat simpulan yang berhubungan dengan sistem pendataan warga yakni: Pembuatan sistem pendataan warga RT 015 berbasis aplikasi java desktop telah mengubah sistem pendataan yang sebelumnya menggunakan metode manual menjadi metode komputerisasi, sehingga memudahkan pendataan secara berkala.

Adapun saran dari penulis mengenai sistem pendataan, yakni mengenai informasi yang masih belum sempurna, sehingga membutuhkan pengembangan dan riset yang memakan waktu lama agar mencapai target dan keinginan yang sesuai.

\section{DAFTAR PUSTAKA}

Andhini, N. F. (2017). Undang-Undang Republik Indonesia Nomor 24 Tahun 2013 Tentang Perubahan Atas UndangUndang Nomor 23 Tahun 2006 Tentang Administrasi Kependudukan Dengan. 53(9), 1689-1699.

Anggraeni, E. Y., \& Irviani, R. (2017). pengantar sistem informasi. Yogyakarta: Andi.

Djahir, Y., dan Pratita, D. (2015). Bahan Ajar Sistem Informasi Manajemen. Yogyakarta: Budi Utama.

Hasugian, H., \& Shidiq, A. N. (2012). Rancang bangun sistem informasi industri kreatif bidang penyewaan sarana olahraga. Semantik, 2(1).

Mulyani, S. (2016). Metode Analisis dan Perancangan Sistem (Vol. 2). Bandung: Abdi Sistematika.

Pressman, R. S. (2015). Rekayasa Perangkat Lunak Pendekatan Praktisi Buku. Yogyakarta: Andi.

Shalahuddin, M. (2014). Rekayasa Perangkat Lunak.

Sukamto \& Shalahuddin. (2013). Analisa dan Desain Sistem Informasi. Yogyakarta: Andi Offset.

Tohari, H. (2014). Astah: Analisis Serta Perancangan Sistem Informasi Melalui Pendekatan UML. Yogyakarta: Andi, 114.

Wulandari, L. T. (2013). Desain dan Perancangan Sistem Informasi Akademik Pada STMIK Ubudiyah Indonesia Banda Aceh. Diambil Dari: Http://Lppm. Stikesubudiyah. Ac. Id/Jurnal/Lestari_Wulandari. $\quad$ T-TwlLestari_wulandari_mi. Pdf. 